\title{
Efficient quasi-solid dye sensitized solar cells employing molten salt electrolyte
}

\author{
G. K. R. Senadeera* and N. de Silva
}

Institute of Fundamental Studies, Hantana Road, Kandy

\begin{abstract}
There have been many attempts to increase the overall conversion efficiency of dye-sensitized solar cells using liquid-state electrolytes. However, this type of cells have unsolved critical problems such as leakage and evaporation of volatile organic solvents. Thus the development of more stable solid or quasi-solid state cell is of great importance. In the study reported here, we developed a novel fabrication method of dye sensitized quasi-solid solar cells using solid composite materials of LiSCN and methyl-hexyl-imidazolium iodide (MHImI) as hole transport materials to replace liquid iodide and polyiodide electrolyte which consists of volatile solvents. The device based on $6 \mu \mathrm{m}$ thick nanocrystalline $\mathrm{TiO}_{2}$ film absorbed by monolayer of $\mathrm{Ru}(\mathrm{II})$ terpyridyl complex photosensitizer (N719 dye), shows excellent incident photon-to-electron conversion efficiency (IPCE, 75\%), large current density (11.6 $\mathrm{mA} \mathrm{cm}^{-2}$ ), and high light-to-electric energy conversion efficiency (5.3- 6.1\%) under the illumination of $100 \mathrm{~mW} \mathrm{~cm}^{-2}$ (AM 1.5).
\end{abstract}

\section{INTRODUCTION}

Dye-sensitized solar cells (DSSCs) are a promising technology for realizing solar cells with high conversion efficiency and low cost compared to silicon-based solar cells [1]. Unlike silicon-based solar cells, however, dye-sensitized solar cells consist of Ru-complex photosensitizers and liquid electrolytes containing redox species $\left(\mathrm{I}^{-} / \mathrm{I}_{3}^{-}\right)$with volatile organic solvents such as acetonitrile [1-4]. The use of liquid electrolyte in DSSCs, however, posses several practical problems including leakage of the electrolyte, desorption of the sensitizing dye by the organic solvent used in the electrolyte, and toxicity of some of the organic solvents. Efforts have been made by many researchers and industrial laboratories to develop practical, high performance DSSCs that combine high efficiency and good stability with easy processability [3-7]. A solid or quasi-solid charge transporting material will avoid

*Corresponding author, e-mail: rsena@ifs.ac.lk 
leakage problems, in addition to allowing easy application of these materials using a cost effective manufacturing process. Solid-hole transport materials and solvent free polymer electrolyte incorporating iodide and triiodide have been introduced to replace the liquid electrolytes, but until now efficiencies of these devices are still relatively low [8-14]. The use of non-volatile liquids or room temperature molten salts (ionic liquids) such as imidazolium salts and pyridinium salts with high ionic conductivity at room temperature would be another solution to the problems. However, viscosities of the molten salts are too high to cause swift $\mathrm{I}_{3}$ - diffusion [7,14]. Papageorgiou et al, have reported that, 10-20\% addition of acetonitrile to room temperature molten salts, increases diffusion rates to keep sufficient electricity [7]. However, they still contain volatile components. It has been reported that the viscosity of imidazolium salts decreased and the photovoltaic performance increased when more than $0.5 \mathrm{M}$ iodine was added to the molten salt [14-16]. Addition of a large amount of iodine increased the short circuit current but decreased the open circuit voltage because of the increase in dark current. Therefore, in this investigation we have focused our attention on the effect of addition of a small amount of LiSCN to ionic type electrolyte on the photovoltaic performances of DSSCs. Here we selected hexylmethylimidazolium iodide (HMImI) as the room temperature molten salt as the source of electrolyte is due to its excellent properties such as negligible volatility, low viscosity and large electrochemical window.

\section{EXPERIMENTAL}

In the fabrication of DSSCs containing nanocrystalline $\mathrm{TiO}_{2}$ films with various thickness, $\mathrm{TiO}_{2}$ paste purchased from “Solaronix” (Solaronix T, Switzerland) was coated by “doctor blade” method (i.e. sliding a paste of semiconductor with a glass rod on the substrate) on pre-cleaned fluorine doped conducting tin oxide (CTO) glasses (Nippon Sheet glass 10-12 $\mathrm{Ohm} \mathrm{sq}^{-1}$ ) and sintered at $500{ }^{\circ} \mathrm{C}$ for 1 hour. The thicknesses of the films on CTO substrates were determined by using a Dektak profilometer (Veeco, Dektack 3). The average thicknesses were $\sim 6 \mu \mathrm{m}$. The sintered electrodes were then immersed in a $5.0 \times 10^{-4} \mathrm{~mol} \mathrm{~L}^{-1}$ Ru dye solution, of N719 solaronix [acetonitrile (ACN)/ tert-butyl alcohol $=1: 1$ ] for $24 \mathrm{~h}$ and rinsed with ACN. Some of the PEC cells were constructed by introducing the redox electrolyte (electrolyte $1, \mathrm{E} 1$ ) containing tetrabutylammonium iodide (TBAI) $(0.5 \mathrm{M}) / \mathrm{I}_{2}(0.05 \mathrm{M})$, in a mixture of acetonitrile and ethylene carbonate $(6: 4 \mathrm{v} / \mathrm{v})$ between the dye coated electrodes and Pt coated counter electrode as shown in Fig. 1. For the other cells, different electrolytes were used as follows. While electrolyte 2(E2) was prepared with 0.2M HMImI/ 0.05M $\mathrm{I}_{2}$ in acetonitrile, electrolyte 3 (E3) was prepared by introducing $0.12 \mathrm{M} \mathrm{LiSCN}$ in acetonitrile to the electrolyte 2 (E3) and then introduced these electrolytes to the dyed electrodes either by dropping or by spin coating. Then the solvent was evaporated at $65^{\circ} \mathrm{C}$ for 60 min under vacuum conditions and cells were then fabricated using a counter electrode as in the previous case.Two external clips 


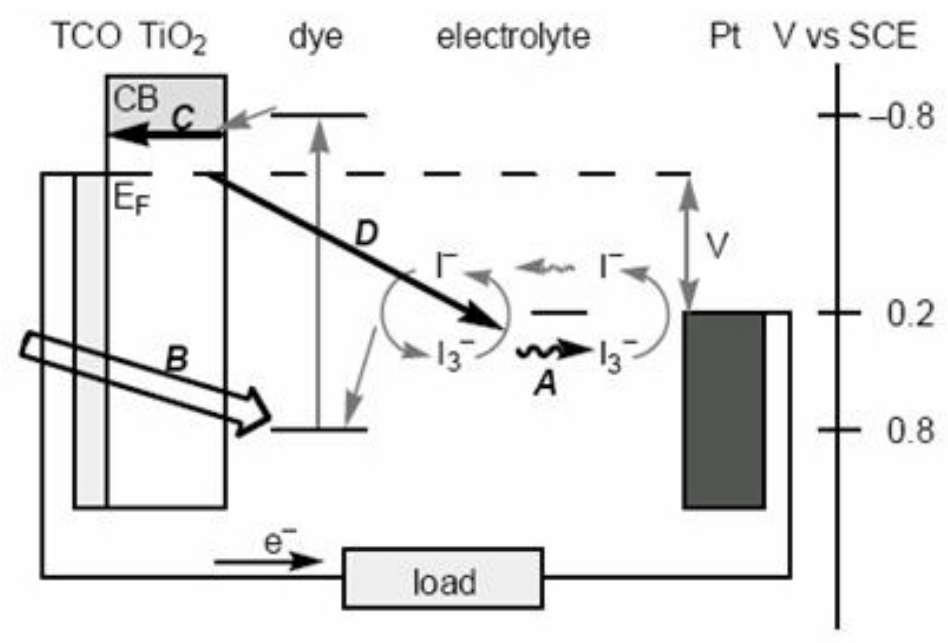

Fig. 1 Schematic description of a $\mathrm{TiO}_{2}$ dye sensitized solar cell, including the energy conversion processes. (A) Diffusion of $\mathrm{I}_{3}^{-}$in electrolyte. (B) Absorption of the incident light by $\mathrm{I}_{3}^{-}$in electrolytes. (C) Diffusion of electrons in the conduction band of $\mathrm{TiO}_{2}$ to TCO. (D) Charge recombination between injected electrons and $\mathrm{I}_{3}^{-}$in electrolyte.

were used to maintain its mechanical integrity from the two opposite sides of the cell, without any further sealing. Photo-energy conversion efficiency was evaluated using standard solar irradiation of $100 \mathrm{~mW} \mathrm{~cm}^{-2}$ (AM1.5) with a solar simulator (YSS-50A, Yamashita Denso) and a computer controlled voltage current source/meter (R6246, Advantest) at $25^{\circ} \mathrm{C}$. The dependence of the shortcircuit current on the incident light intensity was examined, controlling the intensity by using an optical lens and neutral density filters with $\mathrm{H}_{2} \mathrm{O}$ filter to avoid heating of DSSCs by IR light. The effectiveness of a cell to convert light of various wavelengths into electrical energy is measured by the incident monochromatic light current conversion efficiency (IPCE) defined as the number of electrons generated by light per number of photons incident on the cell as formulated by IPCE \%=1240 $J_{\text {sc }} / \lambda W_{\mathrm{i}}$ where $J_{\mathrm{sc}}$ is the short circuit current density $\left(\mathrm{mA} \mathrm{cm}^{-2}\right), \lambda$ the excitation wavelength (nm) and $W_{\mathrm{i}}$ is the photon flux ( $\mathrm{W} \mathrm{m}^{-2}$ ) using a commercial setup for IPCE measurement (PV-25DYE, JASCO) under $5 \mathrm{~mW} \mathrm{~cm}^{-2}$ monochromatic light illuminations ${ }^{1}$. All measured IPCE values were not corrected for the loss of incident light due to the absorption and reflection by the conducting glass support. The optical absorption spectrum of the dye in ethanol was measured with JASCO(V-570) UV-VisNIR spectrophotometer

\section{RESULTS AND DISCUSSION}

Fig. 2 shows the average current-voltage $(J-V)$ curves of the cells fabricated comprising either with electrolytes 1 or 2, under dark and illuminated conditions (AM 1.5, $100 \mathrm{~mW} \mathrm{~cm}^{-2}$ ). While the curve (a) represents the dark $I$ - $V$ behaviour of the cell having electrolyte 1 , the curve $(b)$ shows the same behaviour of a cell with electrolyte 2 . The addition of LiSCN into the electrolyte (E3) showed 


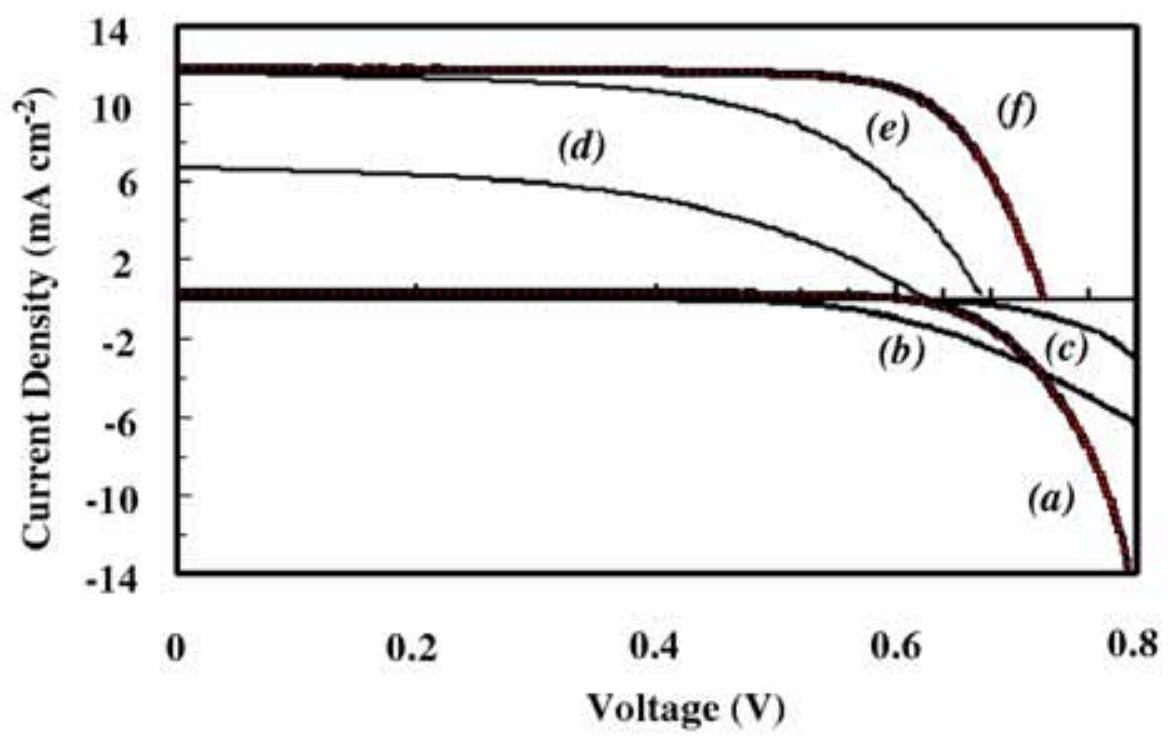

Fig. 2 Dark $I-V$ responses of $(a) \mathrm{TiO}_{2} /$ dye/E1, (b) $\mathrm{TiO}_{2} /$ dye/E2 (c) $\mathrm{TiO}_{2} /$ dye E2/LiSCN and photo responses of (d) $\mathrm{TiO}_{2} /$ dye/E2 (e) $\mathrm{TiO}_{2} /$ dye/ E2/LiSCN and $(f) \mathrm{TiO}_{2} /$ dye/E1.

improved dark current behaviour as shown in curve (c). Curves (d), (e) and (f) show the photoresponses of the above cells. While curves (d) and (e) show the photoresponses of the cells corresponding to electrolyte 2, before (d) and after (e) the addition of LiSCN, the curve (f) shows the corresponding photoresponses of the cell with electrolyte 1 . It should be noted that values of the photovoltaic performances for cells using $\mathrm{HMImI} / \mathrm{I}_{2}$ or $\mathrm{HMImI} / \mathrm{I}_{2} / \mathrm{LiSCN}$ as electrolyte were recorded 12 hours after the preparation of devices. It was found that their performances improved with the time in few hours after preparation, which is due to the improvement of penetration and contact of the electrolyte with dye sensitized semiconductor and counter electrode. This phenomenon also existed in similar cells employing polymer electrolyte [14]. The corresponding values (average of five samples) for the short circuit current density $\left(J_{\mathrm{sc}}\right)$, the open circuit voltage $\left(V_{\mathrm{oc}}\right)$, the fill factor (FF) and the overall solar to electrical energy conversion efficiency $(h)$ are tabulated in the Table 1. As it is evident from the table, significant enhancement could be made in the photovoltaic properties of the cells fabricated with the electrolyte comprising with LiSCN and the cell performances are comparable with those for dye sensitized sensitized cells employing volatile solvent based liquid electrolytes with dyed $\mathrm{TiO}_{2}$ electrodes of the same thickness $(\sim 5.9 \mu \mathrm{m})$.

It was reported that the adsorption or intercalation of cations such as $\mathrm{Li}^{+}, \mathrm{Na}^{+}$, and $\mathrm{Mg}^{2+}$ into a polycrystalline $\mathrm{TiO}_{2}$ electrode are important not only in determining the flat band potential of the electrode but also in the determination of electron diffusion coefficients of the mesoporous electrodes [17]. The lithium salt could screen the field caused by space charge generated under illumination of the heterojunction $[16,18]$ leading to suppression of charge recombination and then to the increase of photo-generated electron on $\mathrm{TiO}_{2}$. The recent laser pulse induced photocurrent measurements 
Table 1. Photovoltaic performances of the cell $\mathrm{TiO}_{2} /$ dye/CuI fabricated under different conditions.

\begin{tabular}{|l|l|l|c|c|}
\hline Cell & $J_{\text {sc }}\left(\mathrm{mA} \mathrm{cm}^{-2}\right)$ & $V_{\text {oc }}(\mathrm{V})$ & FF & EF\% \\
\hline $\mathrm{TiO}_{2} /$ dye/E2 $(d)$ & 6.52 & 0.61 & 0.71 & 2.81 \\
$\mathrm{TiO}_{2} /$ dye/E2/LiSCN $(e)$ & 11.66 & 0.66 & 0.75 & 5.82 \\
$\mathrm{TiO}_{2} /$ dye/E1 $(f)$ & 11.75 & 0.74 & 0.77 & 6.70 \\
\hline
\end{tabular}

[18] revealed that diffusion coefficients of electrons in mesoporous $\mathrm{TiO}_{2}$ systems increase with the increase of cation density on nanaocrystalline $\mathrm{TiO}_{2}$ in the order of $\mathrm{TBA}^{+}<\mathrm{Na}^{+}<\mathrm{Li}^{+}<\mathrm{DMHI}^{+}$. Strong adsorption of imidazolium cations on $\mathrm{TiO}_{2}$ was also confirmed, explaining the inhibition of interface charge recombination as reported in the case of 4-tert-butylpyridine [16]. By considering the above facts, it is possible to conclude that, addition of LiSCN to the electrolyte enhance the photoresponces of the cells, by increasing the photo electrons in $\mathrm{TiO}_{2}$ and reducing the degree of recombination of electron recombination in the system.

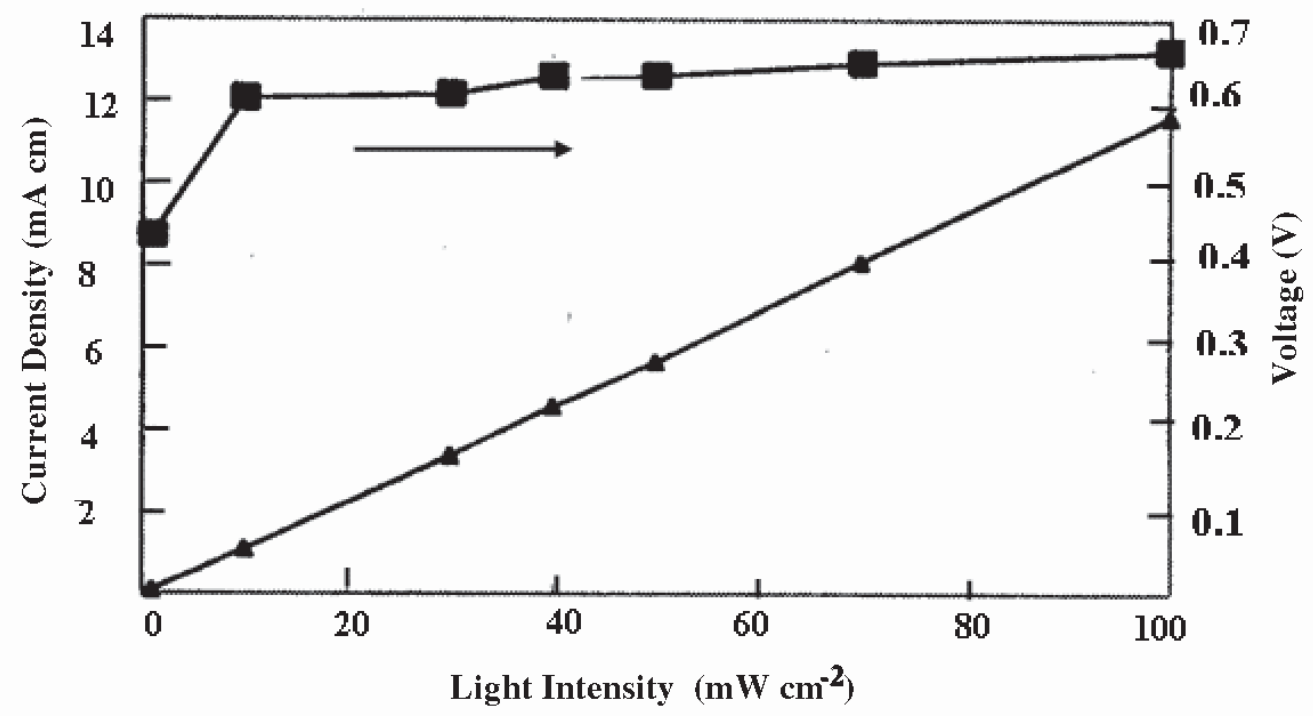

Fig. 3 Incident light dependence of the cell parameters $\left(\mathrm{J}_{\mathrm{sc}}\right.$ and $\left.\mathrm{V}_{\mathrm{oc}}\right)$ of the cell with $\mathrm{HMIm} / \mathrm{I}_{2} / \mathrm{LiSCN}$ electrolyte.

The variation of the short circuit photocurrent density and open circuit voltage with the incident light intensity ranging from 10 to $100 \mathrm{~mW} \mathrm{~cm}^{-2}$ of the cell comprising with new electrolyte (E3) are shown in Fig. 3. While the short circuit photocurrent density linearly increased with increasing light intensity of the incident light, the photo voltage increased slowely from 0.43 to $0.66 \mathrm{~V}$. This indicates that photocurrent is not limited by diffusion of the iodide or triiodide ions within the nanocrystalline film of current densities up to $11.6 \mathrm{~mA} \mathrm{~cm}^{-2}$ which could be ascribed to the improvement of $\mathrm{I}^{-} / \mathrm{I}_{3}^{-}$ions diffusion in the low viscous $\mathrm{MHImI}$. In addition, $\mathrm{TiO}_{2}$ films may have large porosity due to some amount of large particles of $\mathrm{TiO}_{2}$, which could also improve the diffusion of $\mathrm{I}^{-} / \mathrm{I}_{3}$-ions in the film. 
Therefore, it should be emphasized that this feature is an advantage of these cells for practical use under different environmental conditions.

The UV-visible absorption spectrum of the dye in ethanol is shown by curve (a) in Fig. 4 displays an usual intense absorption at $513 \mathrm{~nm}$. The photocurrent action spectra of the cells with similar $\mathrm{TiO}_{2}$ electrodes employing either with the E3 electrolyte or the liquid electrolyte (E1) are shown in Figs. 4 by curves (b) and (c) respectively. Both devices gave the IPCE performances mainly in the 350$600 \mathrm{~nm}$ ranges and the photocurrent action spectra resembled well with the absorption spectrum of the dye.

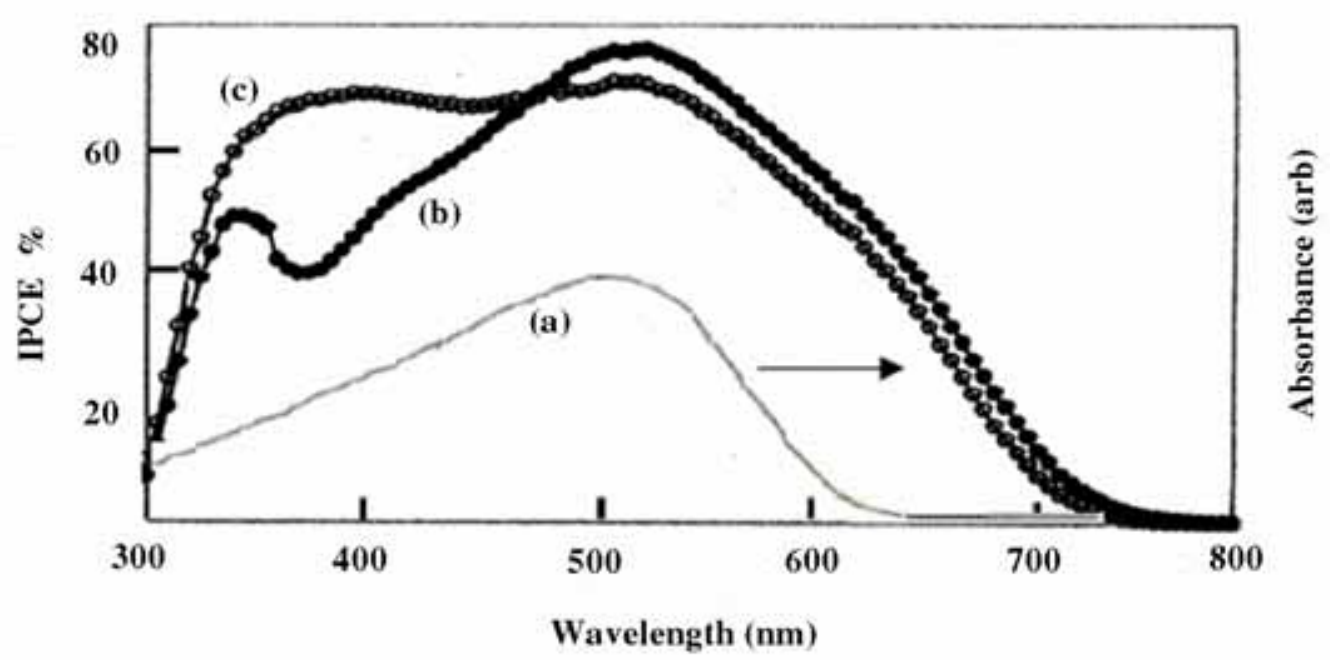

Fig 4. The UV-visible absorption spectrum of the dye in ethanol (a) and the photocurrent action spectra of the cells employing either the HMIm//2/LiSCN electrolyte (b) or the liquid electrolyte (c).

As can be seen from the Fig. 4 higher conversion efficiencies of the cells employing new electrolyte were obtained in the wavelength region ranging from 480 to $800 \mathrm{~nm}$. (The maximum IPCE: 76\% and $71 \%$ at $525 \mathrm{~nm}$ ). The higher conversion efficiencies in this region may come from the higher concentrations of I- ions in the electrolyte compared with that in liquid electrolytes comprising of volatile solvents such as Acetonitrile. It was reported that the high concentration of I- ions can increase the regeneration of the excited dye by obtaining electrons from $\mathrm{I}^{-}$ions $[7,14,16,18]$. In the IPCE spectra, lower conversion efficiencies can be seen clearly in the wavelengths ranging from 300 to $480 \mathrm{~nm}$ compared to those for liquid electrolyte. This result is due to higher conversion of $\mathrm{I}_{3}^{-}$ ions in the HmIMI/LiSCN system, which is more than 20 times compared to that in the liquid electrolyte. The absorption of $\mathrm{I}_{3}^{-}$ions ranges from 300 to $500 \mathrm{~nm}$ with high absorption coefficient, at peaks of 329 and $363 \mathrm{~nm}$ in propylene carbonate, the values of $\varepsilon$ are $2.4 \times 10^{4}$ and $4.5 \times 10^{4}$ respectively. Therefore the dye could not effectively absorb light in this region, which resulted in low IPCE. In addition, the reaction of $\mathrm{I}_{3}^{-}$ions with the electrons at the surface of the dyed $\mathrm{TiO}_{2}$ electrode will increase with their concentration, resulting in back current and the decrease of open circuit 
voltage. According to Table1 it is clear that the cell employing HmIMI/I2/LiSCN electrolyte displays lower $\mathrm{V}_{\text {oc }}$ than the device comprising of the liquid electrolyte.

\section{CONCLUSION}

In conclusion, we have demonstrated that ionic liquid based on $\mathrm{I}_{3}^{-} / \mathrm{I}^{-}$redox couple with LiSCN can be employed as mediators for high-efficiency dye-sensitized solar cells. We achieved $\sim 6 \%$ energy conversion efficiency for a $1 \mathrm{~cm}^{-2}$ cell without nonvolatile organic solvents. An increase in $\mathrm{I}_{3}^{-}$diffusion constants and charge transfer resistance on counter electrode due to the presence of $\mathrm{Li}+$ in the electrolyte might be responsible for the increase in the energy conversion efficiency. Increase in differences between redox potentials and Fermi level of $\mathrm{TiO}_{2}$ should have brought about the increase in $\mathrm{V}_{\text {oc }}$ on LiSCN addition. Work is in progress to further improve the performance of this promising system.

\section{REFERENCES}

1. B. O’Regan, M. Grätzel, A low-cost, high efficiency solar cell based on dye-sensitized colloidal TiO2 films, Nature 353 (1991) 737.

2. M. Gratzel, Photoelectrochemical cells, Nature 414 (2001) 338.

3. M. K. Nazeeruddin, P. Piechy, T. Renouard, S. M. Zakeeruddin, R. Humphry-Baker, P. Comte, P. Liska, L. Cevey, E. Costa, V. Shklover, L. Spiccia, G.B. Deacon, C.A. Bignozzi, M. Gr.atzel, Engineering of Efficient Panchromatic Sensitizers for Nanocrystalline TiO2-Based Solar Cells, J. Am. Chem. Soc. 123 (2001) 1613.

4. K. Hara, K. Sayama, Y. Ohga, A. Shinpo, S. Sugab and H. Arakawa, A coumarinderivative dye sensitized nanocrystalline TiO2 solar cell having a high solar-energy conversion efficiency up to $5.6 \%$, Chem. Commun. 6(2001) 569.

5. K. Hara, M. Kurashige, S. Ito, A. Shinpo, S. Suga , K. Sayama and H. Arakawa, Novel polyene dyes for highly efficient dye-sensitized solar cells, Chem. Commun., 2 (2003) 252.

6. B. O’ Regan, F. Lenzmann, R. Muis, J. Wienke, A Solid-State Dye-Sensitized Solar Cell Fabricated with Pressure-Treated P25-TiO2 and CuSCN: Analysis of Pore Filling and IV Characteristics, Chem. Mater, 14 (2002) 5023.

7. N. Papageorgiou, Y. Athanassov, M. Armand, P. Bonhote, H. Pettersson, A. Azam, M. Gratzel, An Iodine/ Triiodide Reduction Electrocatalyst for Aqueous and Organic Media, J. Electrochem. Soc. 143 (1996) 3099.

8. K. Tennakone, G. R. R. A. Kumara, A. R. Kumarasinghe, K. G. U. Wijayantha, P. M. Sirimanne, A dyesensitized nano-porous solid-state photovoltaic cell, Semicond. Sci. Technol. 10 (1995) 1689.

9. B. O' Regan, D. T. Schwart, Efficient dye-sensitized charge separation in a wide-bandgap $p$ - $n$ heterojunction, J. Appl. Phys. 80 (1996), 4749.

10. K. Murakoshi, R. Kogure, Y. Wada, S. Yanagida, Fabrication of solid-state dyesensitized TiO2 solar cells combined with polypyrrole, Sol. Energy Mater. Sol. Cells 55 (1998) 113.

11. K. Tennakone, G. K. R. Senadeera, D. B. R. A. De Silva, I. R. M. Kottegoda, Highly stable dye-sensitized solid-state solar cell with the semiconductor $4 \mathrm{CuBr} 3 S \tilde{N} C 4 H 9 O ̈ 2$ as the hole collector, App. Phys. Lett. $17(2000) 2367$. 
12. G. K. R. Senadeera, P. V. V. Jayaweera, V. P. S. Perera, K. Tennakone, Solid-state dyesensitized photocell based on pentacene as a hole collector, Sol. Energy Mater. Sol. Cells 73 (2002) 103.

13. G. R. R. A. Kumara, A. Konno, G. K. R. Senadeera, P. V. V. Jayaweera, D. B. R. A. De Silva, K. Tennakone, Dyesensitized solar cell with the hole collector p-CuSCN deposited from a solution in n-propyl sulphide, Sol. Energy. Mater. Sol. Cells 69, (2001) 195.

14. W. Kubo, T. Kitamura, K. Hanabusa, H. Shirai, Y. Wada, and S. Yanagida, Quasisolid-state dye-sensitized solar cells using room temperature molten salts and a low molecular weight gelator, Chem . Com. 4 (2002) 374.

15. U. Bach, D. Lupo, P. Comte, J. E. Moser, F. Weissörtel, J. Salbeck, H. Spreitzer, M. Grätzel, Solid-state dyesensitized mesoporous TiO2 solar cells with high photon-toelectron conversion efficiencies, Nature 395 (1998) 583.

16. J. Krüger, R. Plass, L. Cevey, M. Piccirelli, and M. Grätzel, U. Bach, High efficiency solid-state photovoltaic device due to inhibition of interface charge recombination. Appl. Phy. Lett. 79 (2001) 2085.

17. G. Redmond and D. Fitzmaurice, Spectroscopic determination of flatband potentials for polycrystalline titania electrodes in nonaqueous solvents, Phys. Chem. 97 (1993) 1426.

18. S. Kambe, S. Nakade, T. Kitamura, Y.Wada, and S.Yanagida, Influence of the Electrolytes on Electron Transport in Mesoporous TiO2-Electrolyte Systems, J. Phys.Chem.B 106 (2002) 2967. 